\title{
Boric Acid Catalyzed Convenient Synthesis of Benzimidazoles in Aqueous Media
}

\author{
Mohammad Reza Poor Heravi and Marjan Ashori \\ Department of Chemistry, Payame Noor University, Tehran 19395-4697, Iran \\ Correspondence should be addressed to Mohammad Reza Poor Heravi; heravimr@yahoo.com
}

Received 31 May 2013; Accepted 11 July 2013

Academic Editor: Antreas Afantitis

Copyright (C) 2013 M. R. Poor Heravi and M. Ashori. This is an open access article distributed under the Creative Commons Attribution License, which permits unrestricted use, distribution, and reproduction in any medium, provided the original work is properly cited.

\begin{abstract}
Synthesis of benzimidazoles has been developed by the $o$-phenylenediamine with aldehydes using boric acid an efficient catalyst under mild reaction conditions in aqueous media. The product is applicable to aryl and heteroaryl aldehydes. This reaction led to the formation of benzimidazoles new derivatives in good yields. The FT-IR, ${ }^{19} \mathrm{~F}-\mathrm{NMR},{ }^{1} \mathrm{H}-\mathrm{NMR},{ }^{13} \mathrm{C}-\mathrm{NMR}$ spectra and elemental analysis confirm the structure of compounds.
\end{abstract}

\section{Introduction}

Benzimidazole and its derivatives have been the area of much research interest due to their importance in various applications and its widespread biochemical significance [1]. Benzimidazole structure is found in several classes of drugs based on the substituents present at different positions [2]. Benzimidazole derivatives find many applications in several therapeutic areas such as antimicrobial agents, [3] antiviral agent against several viruses such as HIV, [4] influenza [5], and herpes (HSV-1) [5], antitumor, [6] anti-inflammatory, [7] anthelmintic agents, [8] as well as antiprotozoal agents [9]. The amino ketone derivatives of imidazo [1,2-a]-benzimidazoles are potent adrenoblockers, spasmolytics, antiarrhythmogens, and antimicrobial agents [10]. Benzimidazoles are also important intermediates in organic synthesis [11, 12]. A number of methods have been adopted for the synthesis of benzimidazoles from different reactants and reaction conditions such as reaction between $o$-phenylenediamine and aldehyde under oxidative conditions, [13, 14], $o$ phenylenediamine and carboxylic acid [15-17] in the presence of catalyst such as $\mathrm{H}_{2} \mathrm{O}_{2} / \mathrm{HCl}[18]$, $\mathrm{Sc}(\mathrm{OTf})_{3}[19,20], \mathrm{Cu}$ $(\mathrm{OTf})_{2}$ [21], $\mathrm{KHSO}_{4}$ [22], ionic liquids [23], $p$-TsOH [24], and $\mathrm{SiO}_{2}$ as solid support [25] and under microwave irradiation using polyphosphoric acid as catalyst [26]. However many of these methodologies suffer one or more disadvantages like low yields, lack of easy availability of the starting materials, prolonged reaction time, high temperature, excess requirement of catalysts, special apparatus, harsh reaction conditions, extraction of product, formation of byproduct, and so forth. Thus there is a need for simple and efficient protocol for the synthesis of benzimidazole derivatives. Organic synthesis in aqueous media is rapidly gaining importance in view of the fact that the use of many toxic and volatile organic solvents contributes to pollution. Since the pioneering studies by Breslow [27], on Diels-Alder reactions, there have been profound research activities in the development of organic reactions in aqueous media offering key advantages such as rate enhancement and insolubility of the final products, which facilitates their isolation by simple filtration. Also, in the context of green chemistry, aqueous media is acting as a stepping stone in the greener synthesis of bioactive heterocyclic compounds.

Boric acid is a water soluble catalyst and has been found to be effective in various organic transformations such as esterification of hydroxycarboxylic acids [28], aza Michael [29], thia Michael [30], addition, and bromination [31]. Herein, we report a method for the synthesis of benzimidazole derivatives by using boric acid catalyst to obtain product with high yield in moderate reaction time and easy work-up. 


\section{Experimental}

2.1. Materials and Instruments. Melting point was recorded on a Barnstead/Electro thermal/9200 (England) instrument. All reagents were purchased from Merck. Aldehydes were distilled before use. NMR spectra were recorded using either a Brucker DRX500 machine at room temperature. ${ }^{1} \mathrm{H},{ }^{13} \mathrm{C}$ NMR, and ${ }^{19}$ FNMR spectra were measured using DMSO$d_{6}$ as solvent. $\mathrm{CHN}$ analyses were performed on Exeter Analytical Inc. Model C-400 CHN Analyzer. Mass spectra were obtained using a Micro Mass LCT machine in ES or EI mode. Infrared spectra were measured on a Perkin Elmer Paragon 100 FT-IR spectrometer. All the reactions were monitored by TLC using $0.25 \mathrm{~mm}$ silica gel plates (Merck $\left.60 \mathrm{~F}_{254}\right) \mathrm{UV}$ indicator.

2.2. Typical Procedure for Synthesis of 2-Phenyl-1Hbenzo[d]imidazole (3a). A mixture of $o$-phenylenediamine (107 mg, $1 \mathrm{mmol})$, benzaldehyde (106 mg, $1 \mathrm{mmol})$, and boric acid $(10 \mathrm{~mol} \%)$ in water $(5 \mathrm{~mL})$ was stirred at room temperature for $30 \mathrm{~min}$. After completion of reaction, as monitored by TLC (ethyl acetate/ $n$-hexane, $1: 5$ ) the solid product was collected by simple filtration and washed with water. The crude product (3a) was purified by recrystallization from ethanol.

\section{Spectroscopic Data}

2.2.1. 2-(4-Fluorophenyl)-1H-benzo[d]imidazole (3m). White powder; $201 \mathrm{mg}$ (95\%); mp $237^{\circ} \mathrm{C}$; IR (KBr): 3043, 1408, 1289, 973, $732 \mathrm{~cm}^{-1} ;{ }^{1} \mathrm{H}$ NMR (DMSO- $d_{6}, 500 \mathrm{MHz}$ ): $\delta 13.06(\mathrm{~s}, 1 \mathrm{H}$, $\mathrm{NH}), 8.11$ (d, 2H, $J=8.5 \mathrm{~Hz}, \mathrm{ArH}), 7.77-7.43$ (m, 6H, ArH); ${ }^{13} \mathrm{C}$ NMR (DMSO- $\left.d_{6}, 125 \mathrm{MHz}\right): \delta 151.54,135.09,134.54(\mathrm{~d}$, $\left.{ }^{1} J_{\mathrm{CF}}=253.58 \mathrm{~Hz}\right), 129.87,129.23,127.89,124.54,119.33 ;{ }^{19} \mathrm{~F}$ NMR (DMSO- $\left.d_{6}, 470 \mathrm{MHz}\right):-72.54$; MS (EI), m/z (\%) = $212\left(\mathrm{M}^{+}, 76\right), 116$ (32); HRMS (EI) Found: $\mathrm{M}^{+}, 212.0706$. $\mathrm{C}_{13} \mathrm{H}_{9} \mathrm{FN}_{2}$ requires $\mathrm{M}^{+}$, 212.0701; Anal Calcd for $\mathrm{C}_{13} \mathrm{H}_{9} \mathrm{FN}_{2}$ : C, 73.57; H, 4.27; N, 13.20. Found: C, 73.51; H, 4.31; N, 4.32.

2.2.2. 2-(4-(Trifluoromethyl)phenyl)-1H-benzo[d]imidazole (3n). Yellow powder; $248 \mathrm{mg}$ (95\%); mp $221^{\circ} \mathrm{C}$; IR (KBr): $3095,2199,1625,1451,810,726 \mathrm{~cm}^{-1} ;{ }^{1} \mathrm{H}$ NMR (DMSO- $d_{6}$, $500 \mathrm{MHz}): \delta 12.91(\mathrm{~s}, 1 \mathrm{H}, \mathrm{NH}), 8.09(\mathrm{~d}, 2 \mathrm{H}, J=8.4 \mathrm{~Hz}, \mathrm{ArH})$, 7.89-7.53 (m, 6H, ArH); ${ }^{13} \mathrm{C}$ NMR (DMSO- $\left.d_{6}, 125 \mathrm{MHz}\right)$ : $\delta 159.12,139.14,135.98,126.89\left(\mathrm{q}, J=283.5 \mathrm{~Hz}, \mathrm{CF}_{3}\right)$, 125.45, 122.43, 121.48, 120.09. 116.25; ${ }^{19} \mathrm{~F}$ NMR (DMSO- $d_{6}$, $470 \mathrm{MHz}):-43.25$; MS (EI), $\mathrm{m} / \mathrm{z}(\%)=382\left(\mathrm{M}^{+}, 15\right), 292(65)$; HRMS (EI) Found: $\mathrm{M}^{+}, 267.0713 . \mathrm{C}_{14} \mathrm{H}_{9} \mathrm{~F}_{3} \mathrm{~N}_{2}$ requires $\mathrm{M}^{+}$, 267.0720; Anal Calcd for $\mathrm{C}_{14} \mathrm{H}_{9} \mathrm{~F}_{3} \mathrm{~N}_{2}$ : C, 64.12; H, 3.46; N, 10.68. Found: C, 64.16; H, 4.52; N, 10.71 .

\section{Results and Discussion}

In continuation of our research work using boric acid in organic synthesis here we are pleased to report that a mixture of aldehyde, $o$-phenylenediamine in the presence of boric acid (10 mol\%) in $\mathrm{H}_{2} \mathrm{O}$ at room temperature furnished benzimidazoles in good yields (Scheme 1).
TABLE 1: Model reaction of $o$-phenylenediamine $(1.0 \mathrm{mmol})$ with benzaldehyde $(1.05 \mathrm{mmol})$ by using different amounts of catalyst boric acid in water at room temperature.

\begin{tabular}{lccc}
\hline Entry & Amount of catalyst (\%) & Reaction time (min) & Yield (\%) \\
\hline 1 & 0 & 60 & 0 \\
2 & 5 & 60 & 60 \\
3 & 10 & 30 & 95 \\
4 & 15 & 90 & 90 \\
5 & 20 & 90 & 85
\end{tabular}

${ }^{\text {a }}$ Isolated yield.

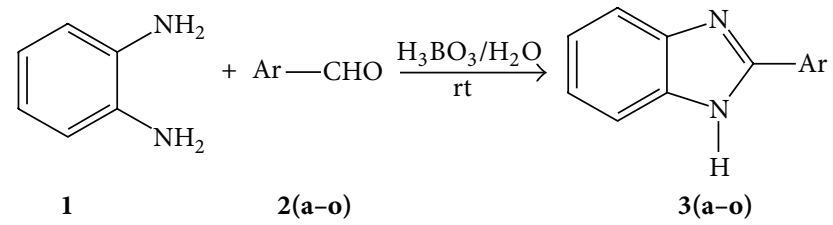

Scheme 1: Synthesis of benzimidazoles using boric acid as catalyst in $\mathrm{H}_{2} \mathrm{O}$.

The reaction was optimized by varying amount of catalyst. We chose the reaction between $o$-phenylenediamine 1 and benzaldehyde $2 \mathrm{a}$ as the model reaction. First we carried out model reaction in the presence of a catalyst (Table 1 , entry 1) and found that the reaction did not proceed. Next, the amount of catalyst was varied with respect to 1 (Table 1 , entries 2-5). It was found that only $65 \%$ and $88 \%$ yields were obtained by taking $5 \%$ and $20 \%$ amounts of catalyst boric acid (Table 1, entries 2 and 5), respectively. The best result (95\% yield of product 3 a) was obtained by using $10 \%$ amount of catalyst (Table 2 , entry 3 ). By using these optimized conditions, various benzimidazole derivatives $\mathbf{3 a -}$ o were synthesized in shorter time as well as in high yields using boric acid as the catalyst.

A wide range of aromatic and heteroaryl aldehydes were subjected to prove the general applicability of our present procedure which is summarized in Table 2. It was observed that the aromatic aldehyde bearing an electron donating substituent underwent the conversion smoothly as compared to that bearing an electron withdrawing substituent (Table 2). We have synthesized compounds 3a-o bearing an electron withdrawing substituent $\left(-\mathrm{NO}_{2}\right) 3 \mathbf{j}$ in $10 \mathrm{~min}$ with high yields were as compounds $\mathbf{3 f} \mathbf{\&} \mathbf{3} \mathbf{i}$ bearing an electron donating substituent $\left(-\mathrm{OCH}_{3} \&-\mathrm{OH}\right.$, resp.) in $60 \mathrm{~min}$.

In ${ }^{1} \mathrm{H}$ NMR spectra of compounds $\mathbf{3 a - o}$, the $\mathrm{N}-\mathrm{H}$ proton of benzimidazole moiety resonates in more down field region, that is, around $\delta 13 \mathrm{ppm}$. The plausible mechanism for the formation of benzimidazole derivative is suggested in Figure 1.

\section{Conclusion}

In conclusion, we have demonstrated a very simple, efficient, and practical method for the synthesis of benzimidazoles with boric acid as catalyst in aqueous media, from readily available $o$-phenylenediamines and aromatic aldehydes, 
TABLE 2: Synthesis of benzimidazole $\mathbf{3 a - o}$ by using boric acid in water.

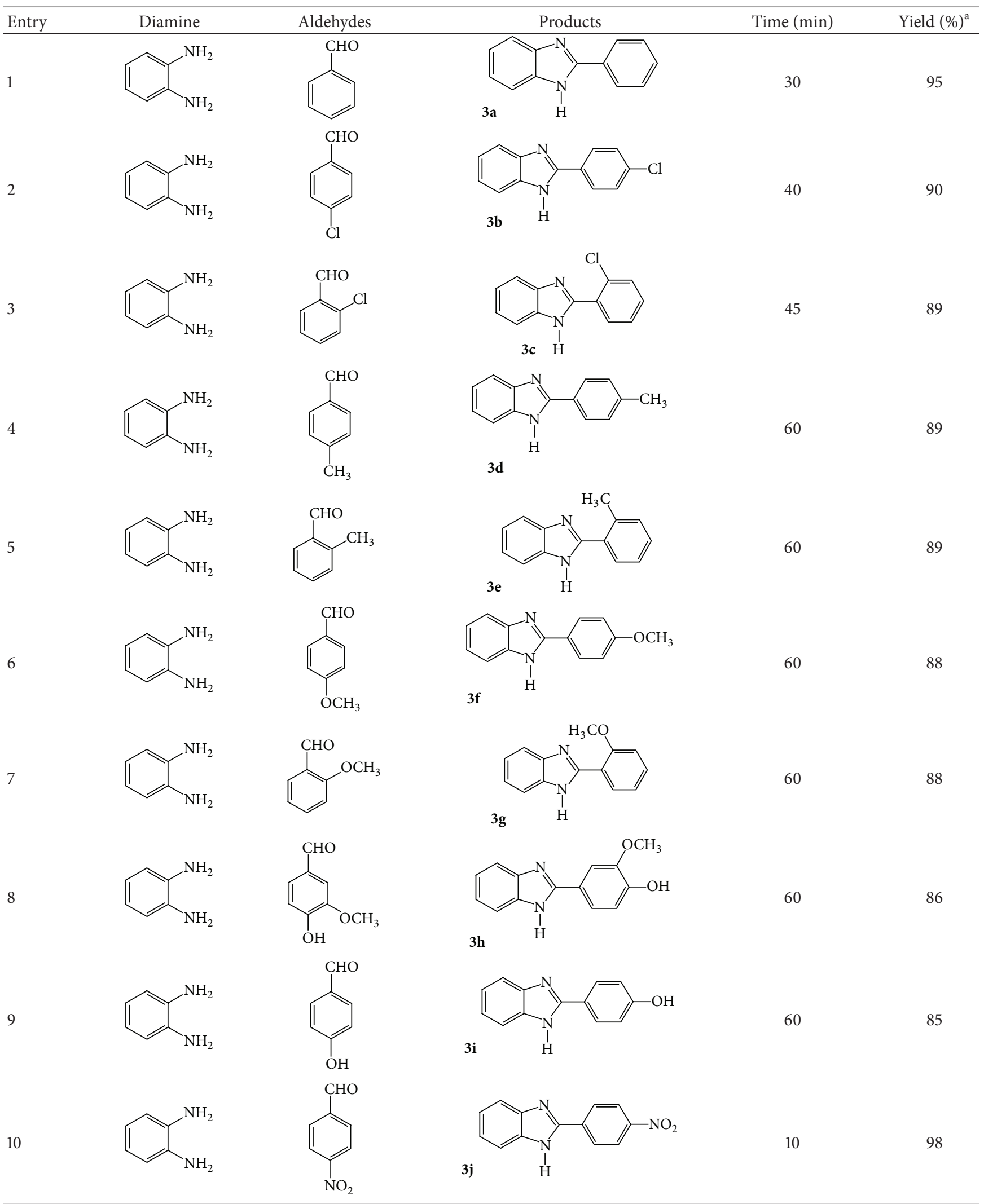


TABLE 2: Continued.

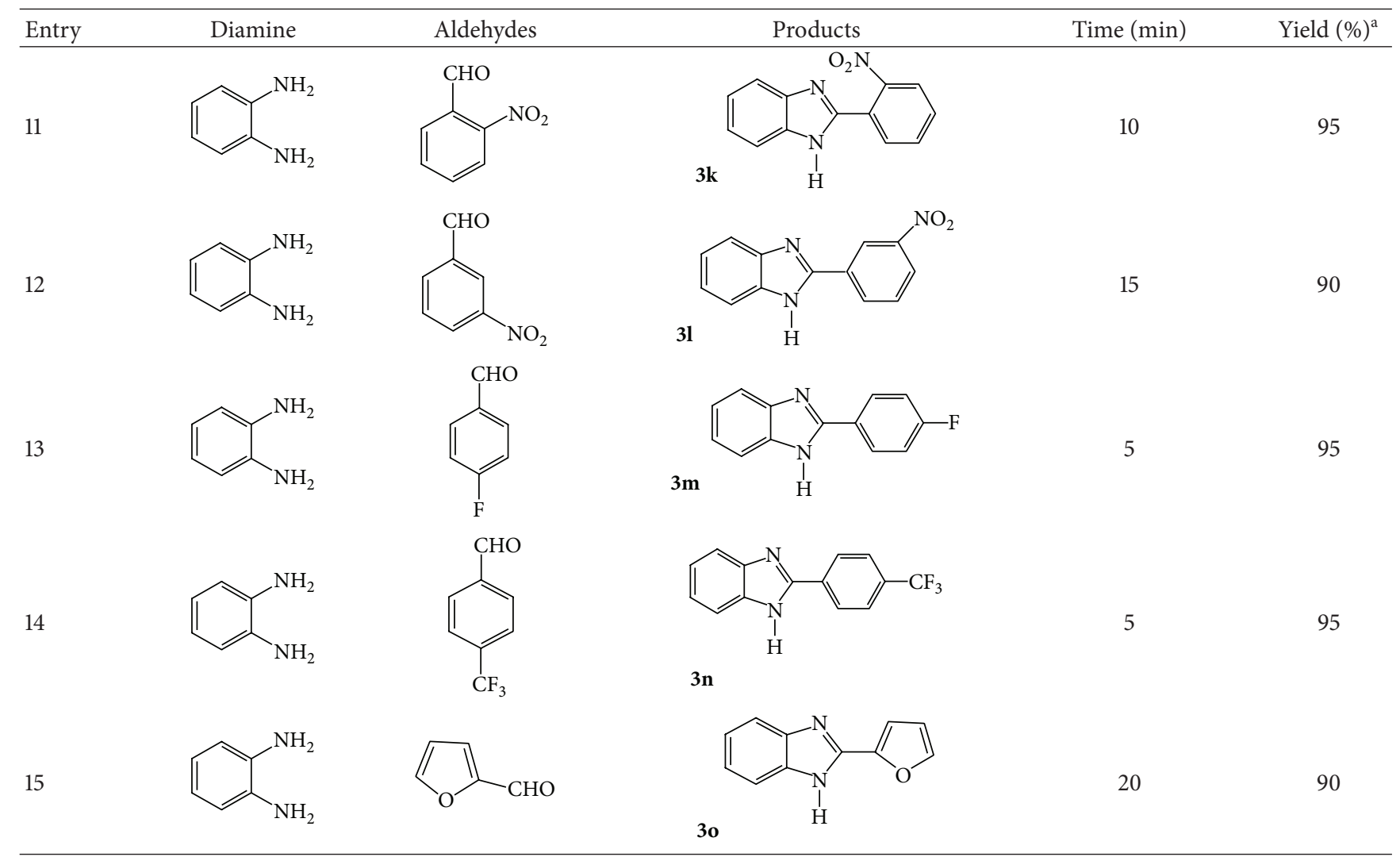

Isolated yield.

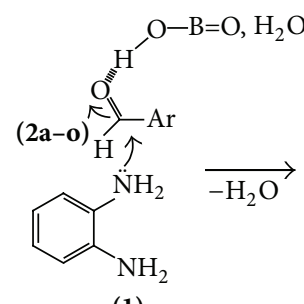

(1)

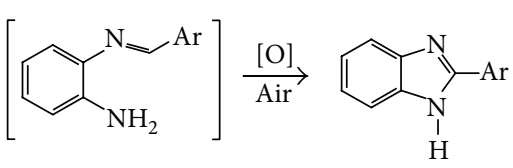

$3(\mathbf{a}-\mathbf{o})$

FIGURE 1: Plausible mechanism for the formation of benzimidazoles.

under simple and convenient conditions. The conditions are mild, and a wide range of functional groups can be tolerated. The main features of our new reaction are as follows: (1) the simplicity of the system; (2) the condensation reaction could be performed exclusively using cheap, commercially available chemicals; (3) easy separation of products from the reaction mixture; (4) the method is cost-effective and environmentally benign.

\section{References}

[1] A. F. Pozhariskii, A. D. Gamovskii, and A. M. Simonov, "Advances in the chemistry of imidazole," Russian Chemical Reviews, vol. 35, no. 2, p. 122, 1996.

[2] J. Velík, V. Baliharová, J. Fink-Gremmels, S. Bull, J. Lamka, and L. Skálová, "Benzimidazole drugs and modulation of

biotransformation enzymes," Research in Veterinary Science, vol. 76, no. 2, pp. 95-108, 2004.

[3] T. Fonseca, B. Gigante, and T. L. Gilchrist, "A short synthesis of phenanthro[2,3-d]imidazoles from dehydroabietic acid. Application of the methodology as a convenient route to benzimidazoles," Tetrahedron, vol. 57, no. 9, pp. 1793-1799, 2001.

[4] T. Roth, M. L. Morningstar, P. L. Boyer, S. H. Hughes, R. W. Buckheit Jr., and C. J. Michejda, "Synthesis and biological activity of novel nonnucleoside inhibitors of HIV-1 reverse transcriptase. 2-aryl-substituted benzimidazoles," Journal of Medicinal Chemistry, vol. 40, no. 26, pp. 4199-4207, 1997.

[5] M. T. Migawa, J.-L. Girardet, J. A. Walker II et al., "Design, synthesis, and antiviral activity of $\alpha$-nucleosides: $\mathrm{D}$ - and L- isomers of lyxofuranosyl- and (5-deoxylyxofuranosyl)benzimidazoles," Journal of Medicinal Chemistry, vol. 41, no. 8, pp. 1242-1251, 1998.

[6] W. A. Denny, G. W. Rewcastle, and B. C. Baguley, "Potential antitumor agents. 59. Structure-activity relationships for 2phenylbenzimidazole-4-carboxamides, a new class of minimal DNA-intercalating agents which may not act via topoisomerase II," Journal of Medicinal Chemistry, vol. 33, pp. 814-819, 1990.

[7] S. M. Sondhi, N. Singh, A. Kumar, O. Lozach, and L. Meijer, "Synthesis, anti-inflammatory, analgesic and kinase (CDK-1, CDK-5 and GSK-3) inhibition activity evaluation of benzimidazole/benzoxazole derivatives and some Schiff's bases," Bioorganic \& Medicinal Chemistry, vol. 14, no. 11, pp. 3758-3765, 2006.

[8] D. Yang, D. Fokas, J. Li, L. Yu, and C. M. Baldino, "A versatile method for the synthesis of benzimidazoles from 
o-nitroanilines and aldehydes in one step via a reductive cyclization," Synthesis, no. 1, pp. 47-56, 2005.

[9] D. Valdez-Padilla, S. Rodríguez-Morales, A. Hernández-Campos et al., "Synthesis and antiprotozoal activity of novel 1-methylbenzimidazole derivatives," Bioorganic \& Medicinal Chemistry, vol. 17, pp. 1724-1730, 2009.

[10] V. A. Anisimova, N. I. Avdyunina, A. A. Spasov, and I. A. Barchan, "Synthesis and pharmacological activity of aminoketones and aminoalcohols of the imidazo[1,2-a]benzimidazole series," Pharmaceutical Chemistry Journal, vol. 36, no. 7, pp. 377381, 2002.

[11] Y. Bai, J. Lu, Z. Shi, and B. Yang, "Synthesis of 2,15-hexadecanedione as a precursor of Muscone," Synlett, vol. 2001, no. 4, pp. 0544-0546, 2001.

[12] E. Hasegawa, A. Yoneoka, K. Suzuki, T. Kato, T. Kitazume, and K. Yanagi, "Reductive transformation of $\alpha \beta$-epoxy ketones and other compounds promoted through photoinduced electron transfer processes with 1,3-dimethyl-2-phenylbenzimidazoline (DMPBI)," Tetrahedron, vol. 55, no. 45, pp. 12957-12968, 1999.

[13] F. Pätzold, F. Zeuner, T. Heyer, and H.-J. Niclas, "Dehydrogenations using benzofuroxan as oxidant," Synthetic Communications, vol. 22, no. 2, pp. 281-288, 1992.

[14] F. F. Stephens and J. D. Bower, "626. The preparation of benziminazoles and benzoxazoles from Schiff's bases. Part I," Journal of the Chemical Society, pp. 2971-2972, 1949.

[15] J. D. Geratz, F. M. Stevens, K. L. Polakoski, R. F. Parrish, and R. R. Tidwell, "Amidino-substituted aromatic heterocycles as probes of the specificity pocket of trypsin-like proteases," Archives of Biochemistry and Biophysics, vol. 197, no. 2, pp. 551$559,1979$.

[16] R. W. Middleton and D. G. Wibberley, "Synthesis of imidazo[4,5 b]- and [4,5 c]pyridines," Journal of Heterocyclic Chemistry, vol. 17, no. 8, pp. 1757-1760, 1980.

[17] J. B. Wright, "The chemistry of the benzimidazoles," Chemical Reviews, vol. 48, pp. 397-541, 1951.

[18] K. Bahrami, M. M. Khodaei, and I. Kavianinia, "A simple and efficient one-pot synthesis of 2-substituted benzimidazoles," Synthesis, no. 4, pp. 547-550, 2007.

[19] T. Itoh, K. Nagata, H. Ishikawa, and A. Ohsawa, "Synthesis of 2-arylbenzothiazoles and imidazoles using scandium triflate as a catalyst for both a ring closing and an oxidation steps," Heterocycles, vol. 63, no. 12, pp. 2769-2783, 2004.

[20] K. Nagata, T. Itoh, H. Ishikawa, and A. Ohsawa, "Synthesis of 2substituted benzimidazoles by reaction of $o$-phenylenediamine with aldehydes in the presence of $\mathrm{Sc}(\mathrm{OTf})_{3}$," Heterocycles, vol. 61, pp. 93-96, 2003.

[21] M. Adharvana Chari, P. Sadanandam, D. Shobha, and K. Mukkantib, "A simple, mild, and efficient procedure for highyield synthesis of benzimidazoles using coppertriflate as catalyst," Journal of Heterocyclic Chemistry, vol. 47, no. 1, pp. 153-155, 2010.

[22] H. Ma, Y. Wang, and A. Wang, "A simple $\mathrm{KHSO}_{4}$ promoted synthesis of 2-arylsubstituted benzimidazoles by oxidative condensation of aldehydes with o-phenylenediamine," Heterocycles, vol. 68, no. 8, pp. 1669-1673, 2006.

[23] H. Q. Ma, Y. L. Wang, J. P. Li, and J. Y. Wang, "Selective synthesis of 2-aryl-1-arylmethyl-1H-1,3-benzimidazoles promoted by Ionic liquid," Heterocycles, vol. 71, no. 1, pp. 135-140, 2007.

[24] X. Han, H. Ma, and Y. Wang, "p-TsOH catalyzed synthesis of 2-arylsubstituted benzimidazoles," Arkivoc, vol. 2007, no. 13, pp. 150-154, 2007.
[25] A. Ben-Alloum, S. Bakkas, and M. Soufiaoui, "Benzimidazoles: oxydation heterocyclisante par le nitrobenzene ou le dimethylsulfoxyde sur silice et sous irradiation micro-ondes ou ultraviolet," Tetrahedron Letters, vol. 39, no. 25, pp. 4481-4484, 1998.

[26] J. Lu, B. Yang, and Y. Bai, "Microwave irradiation synthesis of 2-substituted benzimidazoles using PPA as a catalyst under solvent-free conditions," Synthetic Communications, vol. 32, pp. 3703-3709, 2002.

[27] R. Breslow, "Hydrophobic effects on simple organic reactions in water," Accounts of Chemical Research, vol. 24, no. 6, pp. 159-164, 1991.

[28] T. A. Houston, B. L. Wilkinson, and J. T. Blanchfield, "Boric acid catalyzed chemoselective esterification of $\alpha$-hydroxycarboxylic acids," Organic Letters, vol. 6, no. 5, pp. 679-681, 2004.

[29] M. K. Chaudhuri, S. Hussain, M. L. Kantam, and B. Neelima, "Boric acid: a novel and safe catalyst for aza-Michael reactions in water," Tetrahedron Letters, vol. 46, no. 48, pp. 8329-8331, 2005.

[30] M. K. Chaudhuri and S. J. Hussain, "Boric acid catalyzed thiaMichael reactions in water or alcohols," Journal of Molecular Catalysis A, vol. 269, pp. 214-217, 2007.

[31] J. Nath and M. K. Chaudhuri, "Boric acid catalyzed bromination of a variety of organic substrates: an eco-friendly and practical protocol," Green Chemistry Letters and Reviews, vol. 1, no. 4, pp. 223-230, 2008. 

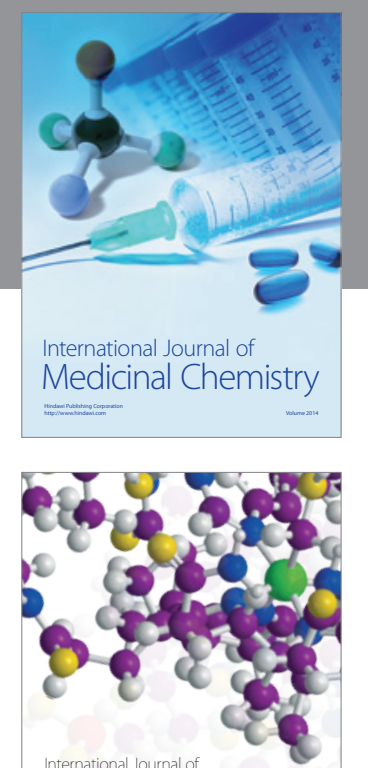

\section{Carbohydrate} Chemistry

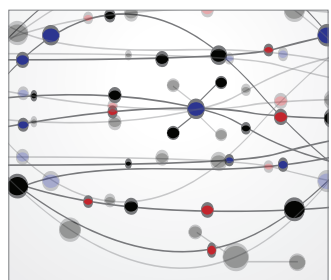

The Scientific World Journal
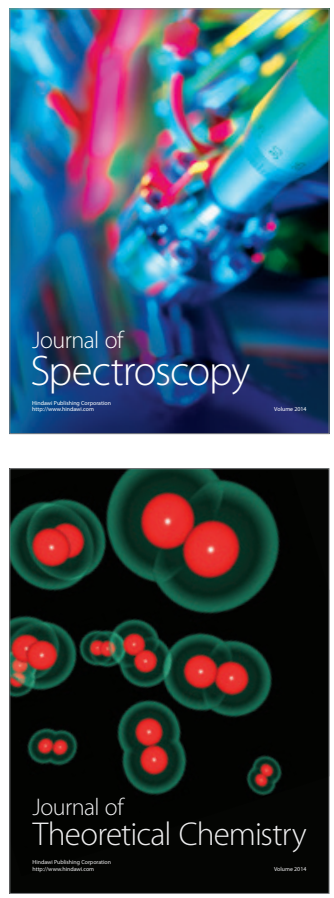
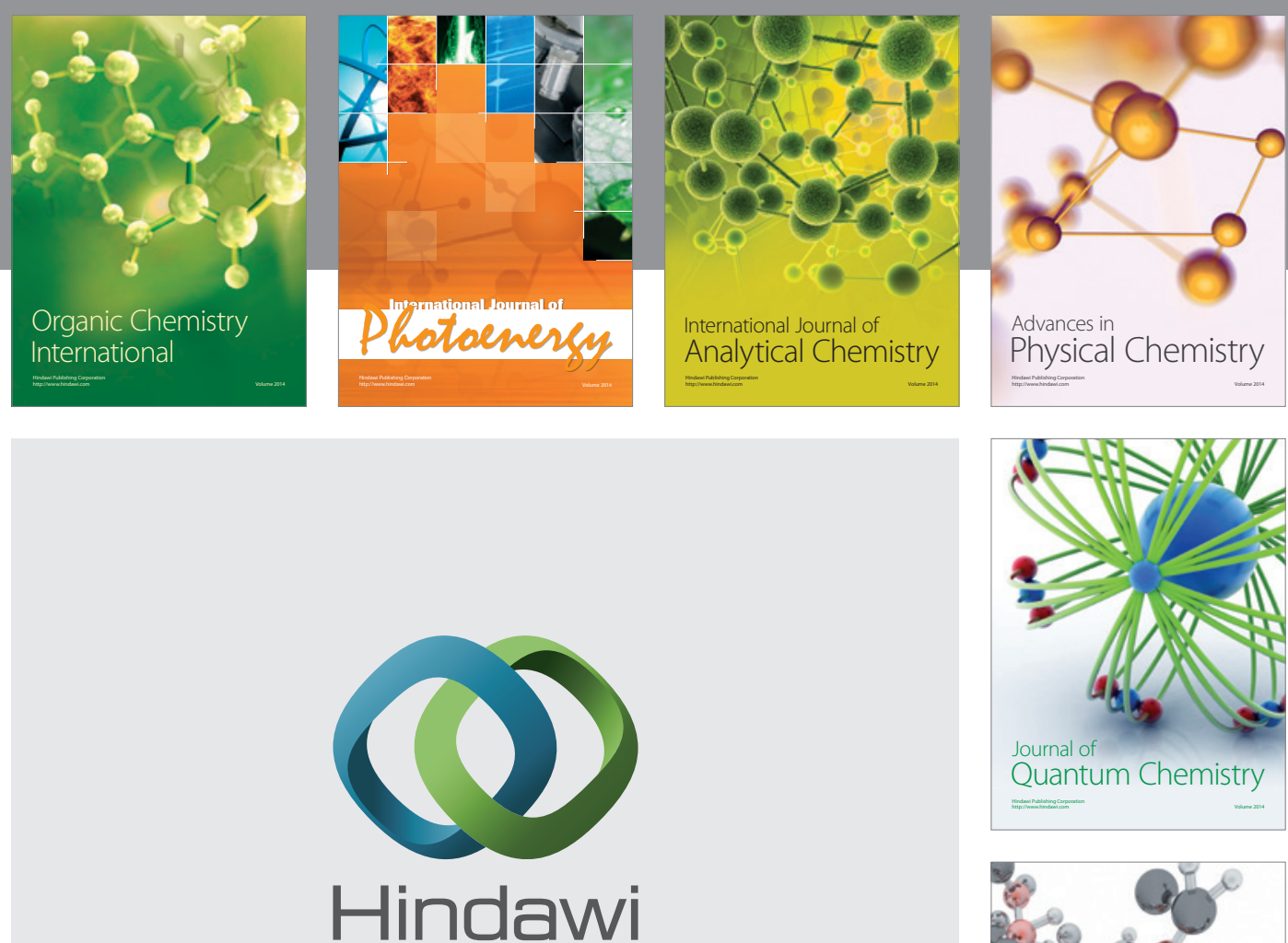

Submit your manuscripts at

http://www.hindawi.com

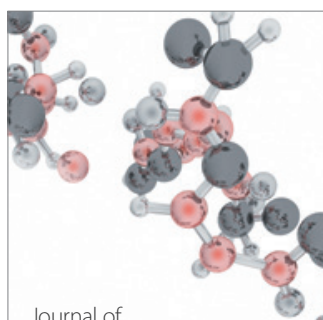

Analytical Methods

in Chemistry

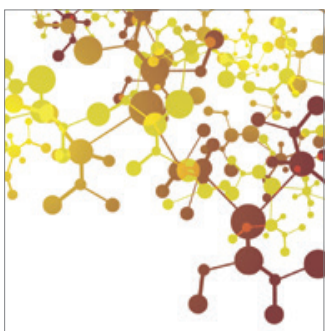

Journal of

Applied Chemistry

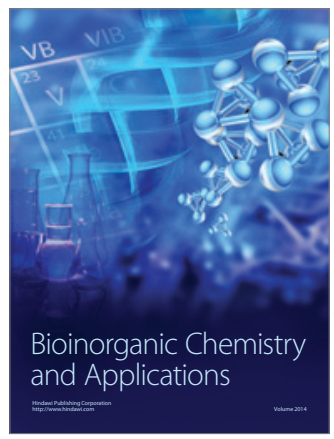

Inorganic Chemistry
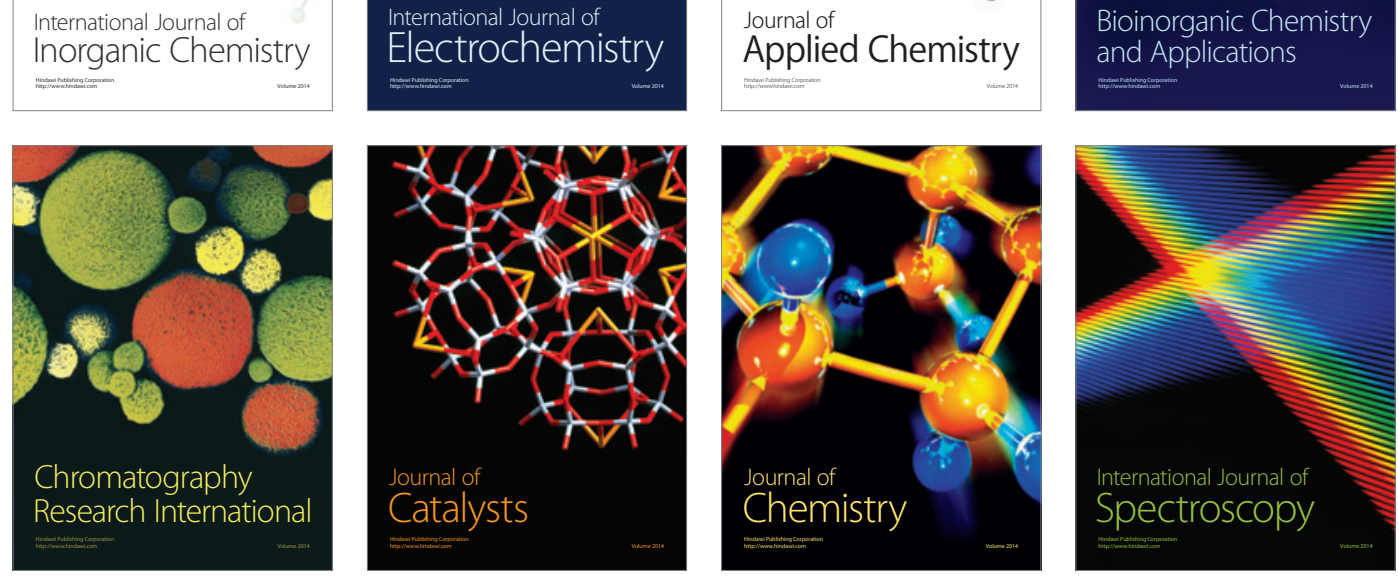